\title{
CORPO E SAÚDE: INCLUSÃO E EXCLUSÃO SOCIAL
}

\author{
Sebastião Jorge Chammé*
}

\begin{abstract}
RESUMO: O tema inclusão e exclusão social é discutido neste texto a partir da concepção de corpo, considerado como um veículo portador de saúde ou de doença em distintos momentos do tempo e de estágios do desenvolvimento civilizatório. Para tanto, o século XX, com seus avanços e recuos é potencialmente considerado fator decisivo na estrutura e organização biopsicossocial do corpo que se apresenta fragmentado, demarcando o cenário da pós-modernidade. Incluído eficazmente, ou não, nos mecanismos das Políticas Públicas destinadas à promoção de saúde, o corpo traduz, a partir dos sintomas de estado de saúde ou estado de doença, o maior ou menor grau de inclusão ou de exclusão social, representado pela inserção e ressonância participativa do usuário dos serviços de saúde - portador de um corpo adoecido -, na desigual realidade em que vive enquanto um sujeito considerado sem saber e sem poder.
\end{abstract}

PALAVRAS-CHAVE: corpo; usuário; saúde/doença; inclusão social; exclusão social; Políticas Públicas.

\footnotetext{
* Sociólogo, Mestre em Ciências Sociais, Doutor em Saúde Pública, Pós-doutorado pelo CERMES-Paris, Livre-Docente pela UNESP Professor do Programa de Pós-Graduação em Educação - UNESP/Marília; Coordenador de Pesquisa do NEPE e Professor nas Faculdades Integradas “Antônio Eufrásio de Toledo” de Presidente Prudente/SP - Rua Fernão Dias, 1076 CEP 19023-280 - Presidente Prudente/SP Telefone 0 (xx18) 222.2926. e-mail chamme @muranet.com.br
} 
O século XX pode ser reconhecido, hoje, no alvorecer do século XXI como tendo sido o tempo dos flagelos! A partir da Revolução Industrial, cidades e áreas industriais cresceram rapidamente sem nenhum planejamento revelando-se carentes dos mais elementares equipamentos sanitários, desde o abastecimento de água, infra-estrutura de esgoto, coleta de lixo e higiene da habitação.

No entanto, é no século XX que a saúde torna-se uma questão pública pelo fato de, após a deflagração da Revolução Industrial, várias ações políticas foram providenciadas por algumas sociedades que se propuseram em fazer avaliações das doenças e, a partir delas, procuraram administrar os denominados índices de saúde (CHAMMÉ, 1996, p. 71). A situação descrita pode ser considerada como um fator determinante para futuras decisões de estruturação de Sistemas Previdenciários na Europa (Alemanha, França e Inglaterra), influenciando, extensivamente, na criação do Seguro Social brasileiro nos anos 30 e 40 no governo de Vargas, tendo exercido influência, ainda, para a construção de distintos modelos de saúde e de corpo considerados ideais em diferentes décadas daquele século, cujo estilo atingiu tanto o corpo dos adultos quanto o das crianças.

Posteriormente às instalações, transformações e unificações legais propostas pelas organizações previdenciárias, foram sendo estabelecidas orientações que diretamente diziam respeito à Saúde Pública, exigindo, para tanto, um planejamento das ações em saúde que pudesse ser considerado eficiente e adequado às exigências do espaço, do tempo, da moda, da mídia, dos desejos típicos das culturas fragmentadas e das frustrações que foram se tornando cumulativas e se transformando em verdadeiros retratos da crise, da desigualdade social, do processamento da exclusão.

Orientações internacionais nos níveis individuais e coletivos passam, então, a estruturar Políticas e Planejamentos em Saúde, no sentido de prevenir doenças e de alcançar o tão desejado estado de saúde. Atualmente, alertados pelos problemas de saúde, criados muitas vezes pelo medo de doenças e até mesmo pelo excesso de zelo, o avanço da Ciência Médica bem como a ampliação das áreas de investigação das Ciências Sociais, saúde/doença/corpo foram sendo enfocados, principalmente a partir das últimas décadas do século recém findado, não mais pela ótica exclusiva das ciências biológicas, suas regras ou formas de legitimação, mas segundo uma visão ampliada que possibilitou fosse alcançado o campo da multidisciplinaridade. 
Assim, a compreensão dos fatores que determinam ou caracterizam o discutível estado de saúde encaminha o problema na direção das condições a que o corpo do sujeito está submetido, principalmente as dos distintos níveis da qualidade de vida que o sustém.

As preocupações assim discutidas ultrapassam a condição do estado de saúde como uma mera aferição do estado de adoecimento. O corpo é indagado em sua dimensão biopsicossocial e seu portador passa a ser visto enquanto totalidade dinâmica e integrada ao ambiente que o cerca (CHAMMÉ, 1996, p. 73).

RICHIR (1993) indaga: "Temos ou somos nosso corpo?" evidenciando que o interesse científico atual no sentido de buscar pela compreensão da condição de saúde está além das condições imediatamente oferecidas pelos dados subjetivos das doenças (sintomas) ou até mesmo os objetivos (sinais), reveladores de sua simples presença ou ausência o que faz reconhecer que a experiência do corpo poderá nortear-se entre dois pólos (o de saúde e o de doença). No entanto, seus determinantes não serão necessariamente ditados pela exclusividade do acometimento biológico mas também pelas condições culturais e simbólicas que configuram sua ampla e complexa identidade.

Corpo enquanto depositário de saúde ou de doença tem sido indagado, desde a vigorosa evolução do século $X X$ avançando além dos riscos biológicos a que está exposto, configurando-se como extensão do sucesso ou insucesso da força do coletivo e do poder individual direcionado na elaboração de seu suspeitado controle.

Neste momento da História Social em que vivemos devemos, pois, considerar os estados de saúde e doença não mais como situações vistas com independência ou isoladamente, mas como partes de um continuum integrado entre saúde/doença/corpo.

O termo saúde, nas últimas décadas do século $X X$, sofreu um processo de total rediscussão, pois, em um passado recente fora caracterizado de acordo com os indicativos de simples ausência ou não de doenças. Em 1947, a Organização Mundial de Saúde formulou o conceito de saúde como sendo o estado de mais completo bem-estar físico, mental e social e não apenas ausência de enfermidade. Tal conceituação, no entanto, apresentou os limites de sua baixa operacionalidade por pressupor parâmetros objetivos e subjetivos de difícil quantificação e, por isso, a discussão que se estabelece é que: no caso da doença, esta se manifesta através de sintomas e sinais que se agrupam em conjuntos e caracterizam as síndromes, ou seja: a doença é passível de ser detectada, pois é uma expressão concreta 
do corpo, enquanto, por outro lado, saúde é tida como uma expressão abstrata e ausente, como se fosse algo que estivesse sempre por vir.

Para as condições controvertidas do binômio saúde/doença encontramos várias referências bibliográficas reveladoras da preocupação de quem perpassou o século $X X$, dentre elas a do olhar cético de ILLICH $(1975$, p.57) para quem uma das maiores epidemias do nosso tempo é causada pela iatrogenia médica. Para este autor: "a sociedade precisa evitar a medicalização da vida, voltar à natureza, aprender a viver com a dor e suportar a morte..."

Nesta mesma direção, outros estudiosos do processo saúde/doença se dispuseram a discutir o tema nos seus diferentes ângulos apontando para a melhoria das condições de saúde segundo medidas preventivas e terapêuticas, ou mesmo, a ascensão da Medicina enquanto um esforço organizado para tornar-se um poderoso grupo técnico-profissional capaz de oferecer proteção ao paciente e dele receber confiança. Dentre os trabalhos que demonstram a preocupação descrita, encontramos os de McKEOWN (1979) e de RELMAN (1984).

Ainda no século XX pudemos assistir aos avanços das Ciências Biológicas e Médicas, bem como nas áreas dos Recursos Tecnológicos, Clínicos, Cirúrgicos, Terapêuticos, nos âmbitos da Saúde Pública e Privada. No entanto, tal evolução ainda está muito longe de ser encerrada, pois os desafios e controvérsias surgidos naquele momento, permanecem sem respostas.

No que se refere aos avanços científicos do século XX na área da Saúde Pública, devemos apontar alguns resultados que são descritos por SCLIAR (1987) como forma de buscar soluções para o desequilíbrio entre os estados de saúde e doença:

- a descoberta de novas vacinas e o aperfeiçoamento das já existentes;

- a descoberta de novos antibióticos e quimioterápicos eficazes contra a tuberculose, as doenças sexualmente transmissíveis, a hanseniase, a pneumonia bacteriana, as doenças causadas por estreptococo;

- drogas parasiticidas e os antimaláricos;

- a disponibilidade de vacinas e drogas, possibilitando programas de massa a nível nacional e internacional; 
- as grandes obras de saneamento básico;

- a fluoretação da água de abastecimento e o uso do flúor por outros métodos;

- a introdução da Terapia de Reidratação Oral e valorização do aleitamento materno;

- a realização de estudos epidemiológicos permitindo a adoção de novos comportamentos e cuidados com a saúde; progênie;

- a demonstração de que o uso da Talidomida em gestantes gerava defeitos na

- melhores cuidados às gestantes e às crianças, em termos de cuidado pré-natal, parto hospitalar, alojamento conjunto visando facilitar o aleitamento, com o objetivo de diminuir a mortalidade materna e infantil;

- a criação do Serviço Nacional de Saúde inglês e os êxitos dos programas de Saúde Pública em países socialistas, mostrando que se pode obter bons resultados em saúde e assistência médica a custos relativamente baixos.

Embora as ações e programas de Saúde Pública tenham produzido efeitos mais rapidamente positivos nos países de Economia mais estável, os meios de comunicação e de difusão foram auxiliares para que tais medidas alcançassem também os países mais pobres.

A contradição, no entanto, está no modo como a generalização das informações, em especial aquelas que se referem aos hábitos sobre saúde se impõem à população que padece de outras tantas precariedades. O mais grave é que, à medida em que se incorporam ao cotidiano da classe subalterna, as ações não têm ocorrido como condição formativa ou educativa, ficando relegadas simplesmente ao plano informativo.

Como decorrência da referida constatação, temos que os valores que vêm de fora, pelo fato de não serem partes originais das ações cotidianamente vivenciadas pelo agrupamento social, instalam-se nele, no geral pela via normativa e impositiva e, ao invés de se tornarem uma forma de aprendizado útil e consciente, reduzem-se ao mero cumprimento de tarefas impostas pelas regras, concretizando-se como simples comportamento imitativo sem qualquer referencial de originalidade.

Tal condição traduz ações cumpridas, mas não referendadas, ou seja: rotinização e automatização de condutas que obedecem a um planejamento massificado do saber 
elaborado fora do contexto cultural de origem dos sujeitos-alvo, cujo poder, que lhe seria próprio, fica reduzido a nenhum grau de importância. É assim que os indivíduos reagem, por exemplo, com relação às doenças sexualmente transmissíveis (CHAMMÉ, 2000, p. 274).

Devido ao bombástico alarmismo das Campanhas, o medo daí resultante não se traduz em ações preventivas, mas em preconceitos que não se transformam nem em poder declarado de policiamento da doença e tampouco de vigilância à saúde.

O corpo, por sua vez, reduz-se em depositário falível de males, fruto tanto do insucesso da força do coletivo, quanto do poder individual.

O aperfeiçoamento das tecnologias médicas para a busca da cura é revelador do próprio processo de crise da saúde para a população mundial, pois, na medida em que busca-se por ações terapêuticas, condutas básicas, vigilância sanitária, ressalta-se a existência de uma multiplicidade de fatores não exclusivamente biológicos que demonstram o quanto sociedades inteiras têm se arriscado pela saúde no jogo desigual e injusto das doenças!

Resultado disso: a população mundial sofreu, nos últimos anos, um processo de explosão demográfica em velocidade insuspeitável, urbanizou-se como pôde, excluiu camponeses, selecionou elites, estilos e modas, distinguiu minorias, criou periferias, marginalizou os homens das cidades, gerou expropriados, concentrou o capital econômico multifacetando o capital cultural, eliminou distinções entre classes sociais com promessas do porvir garantindo, em contrapartida, subalternidades.

A hegemonia torna-se a arma ideal para garantir a imutabilidade das condições de vida e do estado de bem-estar, produzindo um sujeito aprisionado, sem saber e sem poder!

$\mathrm{Na}$ esfera da saúde física e mental, o sujeito inserido nas caóticas condições descritas, torna-se, naturalmente, portador de um corpo estressado e tão espoliado quanto o capital que não possui e a educação da qual não faz parte. Sua saúde? Igualmente expropriada!

A situação descrita sugere uma infinidade de exclusões e explorações frutificadas no decorrer de todo o século XX, traduzidas em doenças. 
Deveria a condição de saúde, tanto quanto o estado saudável dos sujeitos, serem apresentados como resposta à conjuntura econômica, já que são tão discutidos como fatores de desenvolvimento?

Embora as contradições desta discussão existam, não restam dúvidas de que o controle das doenças numa determinada região poderia propiciar o desenvolvimento sócioeconômico ou mesmo tornar-se um de seus fatores coadjuvantes. Historicamente, o que assistimos, tem sido o contrário.

No que se refere ao processo de Educação Sanitária, o de Educação para a Saúde tem sido elaborado segundo um recorte paternalista e autoritário e, por tal razão, "as formas de manifestação corpórea obedecem a uma ressonância social onde a rede simbólica traduz a especificidade da relação que o indivíduo faz com o mundo" (CHAMMÉ, 1994, p. 33), quando o esperado seria: educadas, as pessoas adotariam medidas para evitar a doença $e$ manter a saúde. $O$ mesmo acontece com outros tantos programas propostos pela Saúde Pública.

Nestas condições, ficam estabelecidas as relações mais amplas do processo de dominação/subordinação capazes de garantir a manutenção da estrutura social tradicionalista e dos esquemas autoritários que aprisionam os indivíduos dentro dos limites da originalidade do status quo visto como imutável e eternizado.

Embora as medidas, procedimentos e investimentos que as Políticas Públicas têm se esforçado em oferecer à população brasileira, no sentido de estabelecer programas de saúde, os problemas enfrentados - seja por desproteção orgânica, social ou multicausal -, têm sido progressivamente agudizados diante dos níveis da má qualidade de vida que colocam em risco o estado de saúde dos sujeitos.

Surgiu, no século XX, a figura do usuário, que se tornou um elemento de destaque no cenário da Saúde Pública. É ele o sujeito-sustentáculo dos desacordos e desacertos da baixa qualidade de vida, da falta ou do mal destino das verbas públicas, do desestímulo político, do processo solidário da repartição da miséria entre os subalternos, da Educação para a doença, fatores que o vitimam com freqüência e $o$ encarceram num processo de marginalização sócio-cultural. Contudo, os programas e ações planejadas pela Saúde Pública visam atendê-lo! (CHAMMÉ, 2000, p. 276). 
O usuário é ainda caracterizado como sendo o proprietário e portador do corpo adoecido que perambula pelos Serviços Públicos de Saúde, buscando por especialidades médicas, idealizadas (para ele!) como sendo possivelmente salvadoras!

Assim, o usuário assume um discurso sobre seu corpo adoecido visando traduzi-lo e, ao mesmo tempo traduzir-se, através de uma infinidade de sintomas resultantes de sua falência orgânica, de sua descrença no presente e igualmente no futuro, da sua condição de expropriação e da conseqüente marginalidade. Aliado à sua hipocondria individual, somase, então, uma hipocondria institucional que bem caracteriza o Sistema de Saúde, o qual, em não alcançando soluções ou medidas eficazes para o sucesso da saúde do sujeito adoecido, vai-lhe condicionando cada vez mais às regras e rotinas do próprio Sistema, favorecendo seu processo de metamorfose de um simples usuário dos serviços públicos de saúde, à condição de poliqueixoso (CHAMMÉ, 1992; 2000).

É assim que, ao longo de todo o século $X X$, o binômio saúde/doença ganhou lugar no cenário das Ciências Biomédicas e mereceu atenção crítico-interpretativa por parte de vários outros domínios científicos, com destaque para as Ciências Sociais.

Pesquisas quantitativas e qualitativas, como as discutidas por BAUMANN (1961), CASSEL (1976), EISENBERG (1977), UNGLERT (1986 e 1995), BARTHE (1990), AÏACH et CÈBE (1991), CHAMMÉ (1992 e 1997), abordaram os mais distintos problemas que envolvem a temática, promovendo concepções, modismos, planejamentos, formulações políticas. Saber e poder foram considerados, nos diversos estudos, como pertencentes ora ao poder hegemonicamente instalado pelas elites, ora aos que não detinham absolutamente poder algum: os subordinados.

Desta forma, distintas camadas, culturas e grupos sociais, buscaram explicar as causas relacionadas à saúde e à doença às crenças sobre tipos de tratamentos e a quem recorrer quando estivessem doentes (UNGLERT, 1986).

Tomando em consideração as doenças que caracterizaram todo o século XX e que trouxemos como herança para o século XXI, temos idéia da degenerescência dos organismos que as transportam e do grau das neuroses que elas acarretam, ou seja, vivenciamos um período da história da humanidade onde o risco da falência orgânica, do contágio e da contaminação são uma constante. Dada a gravidade do caso, ao referir-se ao corpo, os discursos proferidos estão freqüentemente voltados e atentos para os perigos que representam. 
Os testemunhos sobre doenças acabam, então, tendo prioridade em relação aos testemunhos sobre saúde.

A literatura científica tem apresentado uma multiplicidade de análises que se prendem ao tema saúde enquanto preocupação de investigação. HERZLICH e PIERRET (1988), AÏACH et CÈBE (1991), dentre outros, afirmam não obter referências exclusivas sobre saúde senão enquanto instância da condição de períodos de ausência de doenças.

Assim, conotar saúde enquanto condição de estado de não doença, ou mesmo da ausência de doenças, tem sido uma constante, revelando a dificuldade que os próprios sujeitos encontram para a expressão do seu corpo sentido/pensado.

Imaginários e representações, ambos referidos sobre o corpo/cotidiano, mediante os riscos de gravidade, contaminação, contágio, que estiveram presentes no decorrer do século $X X$, chegam a ser uma ameaça para o século XXI, o novo milênio, no que concerne à abertura dos horizontes do cotidiano, não obstante o avanço das pesquisas científicas que têm afirmado as limitações a serem vividas nesta nova realidade ameaçadora da virulência dividida entre os sujeitos, ultrapassando barreiras de ordem política, geográfica, econômica, cultural e individual.

A consciência veiculada entre corpo $\mathrm{x}$ ameaça de riscos $\mathrm{x}$ doenças $\mathrm{x}$ morte tem delineado imaginários e representações dos sujeitos já inseridos no conhecido processo de Educação para a doença, de acordo com as discussões construídas por CHAMMÉ (1994). Assim, tal fato é considerado limitante para a hipótese de investigação do estado de saúde exclusivamente para uma amostragem de sujeitos que apresentem um discurso sobre corpo saudável. Saúde e doença são, pois, constitutivos de uma mesma realidade representada no corpo, obedientes a uma lógica estabelecida no tempo social, ordenada segundo os parâmetros de uma cultura típica das condições excludentes do estado de doença.

Do ponto de vista da Educação, no seio de uma mesma cultura, os indivíduos dispõem de um certo registro corporal comum, que bem reúne sensações e expressões as mais correntes da vida coletiva, bem como os traços pessoais e corporais, cuja configuração é também o tracejar sensível da sociabilidade igualmente comum.

Nesta situação, as formas de manifestação corpórea (frente à alegria, tristeza, saúde, doença) obedecem a uma ressonância social onde a rede simbólica traduz a especificidade da relação que o indivíduo faz com o mundo (CHAMMÉ, 1994, p.33). 
Aprendizado e imitação conjugam efeitos que são sustentados pelo processo de identificação que vai impregnando, pouco a pouco, cada membro que convive com alguém em estado de adoecimento/padecimento, de uma simbologia corporal culturalmente admitida pelo grupo.

Complementando tal raciocínio, lemos em LE BRETON (1982, p.225), que: “... a socialização do corpo exige a presença de outrem e implica também em sua permanência...”

Sugere-se, assim, haver uma interdependência do corpo no interior de uma mesma trama sóciocultural, favorecendo a educação para a doença que, mais que uma declarada intenção formal é resultado de informalidades ritualizadas, garantidas, principalmente, pela continuada presença de outros participantes da mesma simbologia cultural, vivenciando, direta ou indiretamente, os hábitos e a conduta social, dividindo códigos que, no geral, são decodificados em uma linguagem popular, favorecendo o processo do aprendizado sobre estar doente ou estar sadio, que têm como princípio, o saber não elaborado.

No entanto, de queixa em queixa, o referido saber vai sendo elaborado e passa a fazer parte dos traços culturais da cultura geral, garantindo, assim, um contingente populacional ainda não adoecido, porém, culturalmente equipado para defender-se das prováveis/futuras doenças, educando-se para a rotinização das queixas, das suas dificuldades e construção de argumentos.

Educação enquanto um processo amplo e culturalmente significativo de estimulação e motivação, tendo como objetivo a elaboração e (re)elaboração do saber, ao adotar como conteúdo a ser ensinado/aprendido os indicadores saúde/doença/corpo, o resultado termina por ficar submetido ao desempenho dos papéis sociais dos reprodutores da cultura da doença. $O$ imaginário de adultos e crianças assim organizado, estrutura pensamento, sentimento e conhecimento a respeito de saúde e de corpo, exclusivamente, segundo os moldes previstos pelo estado de doença.

Em decorrência dos interesses da população envolvida em diversos movimentos sociais que visam à conquista da cidadania, teorias educacionais gerais e, notadamente, em saúde, foram sendo propostas nos últimos anos.

Homens de ciência procedentes de diferentes domínios, têm colaborado com tal proposta investindo na multidisciplinaridade necessária à compreensão ampliada do processo de educação em saúde, acumulando conhecimentos e constituindo projetos que se estendem para as sociedades, para a cultura nelas instaladas e alcança os sujeitos em seus cotidianos. 
Porém, na medida em que a superioridade dos homens em relação ao conhecimento e ao saber vai se desenvolvendo em busca do domínio sobre a natureza e sobre o próprio homem, são geradas, concomitantemente, hierarquia e coação, colocando os projetos de Educação em saúde em um plano secundário e não significativo.

O descaso típico e o desinteresse das Políticas Públicas pelo tema têm favorecido, sobremaneira, o envolvimento dos sujeitos no processo de educação para a doença. Via de regra, mais que uma declarada intenção formal, este tem sido o resultado de verdadeiras informalidades ritualizadas entre aqueles que se utilizam dos serviços públicos de saúde. Os programas e campanhas de saúde têm procurado explorar uma linguagem popular no sentido de favorecer o processo do aprendizado em saúde e, no entanto, o que conseguem é o reforço da conduta negativa da população que, cada vez mais, adota comportamentos supostamente previdentes sobre estar doente ou sadio, que têm, como princípio, a manutenção do saber não-elaborado.

A relação de dependência proveniente do processo de dominação/subordinação perfaz, nestas circunstâncias, uma relação de equilíbrio e, em sendo mantida, assume condição de estabilidade. Conseqüência do fato, contrastes e conflitos, não satisfação das necessidades e falta de educação para a saúde vão se acentuando, enquanto os meios de comunicação de massa, a publicidade e a propaganda, ao invés de instalarem, para o conjunto de conhecimentos da população conceitos novos e úteis ao seu estado de saúde, aniquilam, abatem, garantindo-Ihes, enquanto sujeitos adoecidos, um não-lugar social.

No caso da Saúde Pública, estiveram sempre na retaguarda do processo educacional e dos movimentos sociais - seguramente instaladas -, as ordenações políticas organizadas e esquematizadas segundo um pensamento considerado coerente para cada estágio da história dos homens, comunicando, no geral, a vontade de uma minoria sobre o comportamento da maioria, a qual esteve freqüentemente subordinada, obediente, alheada, revelando condutas padronizadas e niveladas por baixo.

A condição descrita tem sido o grande contributivo para a discutida Educação para a doença, bem como para a inércia em que os movimentos sociais têm estado ultimamente, fato que reflete a supremacia e a garantia do poder instalado e controlado por verdadeira elite que, infelizmente, em se sentindo obedecida, vê, no poder, uma extensão do seu saber.

Tal fato traduz, se visto pelo lado do aparente, que os detentores das Políticas Públicas são aqueles mesmos que elaboram e controlam o conhecimento, tanto teórico 
quanto prático, sobre as reais necessidades de saúde da população adoecida, concretizando, assim, um verdadeiro processo de inversão de valores, situação para a qual a crítica construída sobre o processo da hegemonia ideológica constata: quem melhor que a própria população usuária para discutir, apontar, resolver, propor, refletir, decidir, sobre suas próprias condições de saúde, tanto quanto a mais adequada maneira para apresentar seus problemas de saúde, propondo, inclusive, saídas, condutas e normas sobre os serviços que a ela são oferecidos, alternativas sobre suas ações ritualizadas na busca pela cura, novas estratégias, limites e possibilidades, senão ela própria?

Neste sentido, tanto a Saúde Pública quanto a crítica das Ciências Sociais têm assistido, nos últimos anos, a discussões que apontam para a ineficiência sobre as tradicionais ações autoritárias sobre o que verdadeiramente se pretende conceber como eqüidade e acesso à saúde, dentre elas, os trabalhos de UNGLERT (1986 e 1995), HERZLICH e PIERRET (1988), CHAMMÉ (1992 e 1997).

Tais investigações sugerem revisões sobre os planejamentos em saúde, tendo em vista múltiplos enfoques, tais como o geográfico, o cultural, o saber dos próprios enfermos sobre suas enfermidades, as características de suas queixas, bem como seus discursos, segundo o saber que possuem sobre seus próprios corpos adoecidos e seus cotidianos.

No decorrer da história dos homens, que é fidedignamente acompanhada pela própria história da saúde e da doença, temos assistido, atônitos, a um exercício de verdadeiro controle social. Este termo é discutido como sendo: “... o conjunto das sanções positivas e negativas a que uma sociedade recorre para assegurar a conformidade das condutas aos modelos por ela estabelecidos" Mac IVER \& PAGE (1972, p.143).

Assim concebidas as formas de controle social, no geral estabelecidas pelas Políticas Públicas - sempre em nome da boa higiene e do estado de salubridade ideal e desejado por todos -, somos levados a deduzir, no caso da Saúde Pública, que os sujeitos sociais, a nível individual e/ou coletivo, temendo pelas sanções advindas do não cumprimento das imposições expressas pelas regras, adotam, como padrão incontestável de conduta, diretrizes propostas por outrem que não os próprios interessados: eles mesmos.

Dentre as justificativas comumente proferidas pelas esferas políticas, teria sido o temor pela eficácia do controle social uma das causas reais do não total sucesso obtido pelos movimentos populares que reivindicavam saúde numa concepção ampliada a partir 
das discussões da 8ª Conferência Nacional de Saúde em 1986 que, por sua vez, alcançaram a Constituição Federal de 1988?

Estariam as camadas subalternas brasileiras, naquele momento, despreparadas para enfrentar a luta pela cidadania e direitos à saúde? Ou, teria sido a própria extensão do novo conceito de saúde tão lógica e amplamente descrito que teria ultrapassado o nível de atuação por parte dos cidadãos? Enfim, em pleno avanço do século XXI, tudo fica mantido como outrora, ou seja: desigual, porque útil!

Assistimos, então, no presente, a um processo de inteiro consentimento por parte da população (considerada pelo poder público como sendo ignorante, despreparada e deseducada) para com as idéias dos teóricos (considerados pela população como sendo conhecedores científicos sobre as doenças), porém totalmente alheadas do real conhecimento sobre os doentes...

No entanto, modernos planejamentos em saúde e os de formação de médicos, sinalizam a intenção de resgatar o espírito participativo da população para a qual os serviços de saúde devem ser destinados.

Embora benéfico e adequado, tal procedimento não deve ocorrer no sentido de tomar de assalto o poder de decisão, retirando das mãos do poder político o conhecimento científico sobre medicina, processo de diagnóstico, de tratamento ou de intervenções necessárias, mas visando buscar por um processo de gestão conjunta de real exercício de cidadania que pudesse levar em conta o saber não elaborado típico das queixas e dos discursos sobre corpo/saúde/doença que a própria população constrói, ocasião esta em que pudesse ser dividido com ela o quinhão que the cabe: o da participação com responsabilidade no processo de decisão sobre sua própria saúde e vida.

\section{REFERÊNCIAS BIBLIOGRÁFICAS}

AIACH, P \& CÈBE, D. Expression des symptômes et conduites de maladies. Paris: Doin, 1991.

BARTHE, J.F. Connaissance profane des symptômes et recours thérapeutique. Revue Française de Sociologie, Paris, v.31, n.2, 1990. 
BAUMANN, B. Diversities in conceptions of health and physical fitness. Journal of Health and Human Behaviour, Washington, v. 2, p.39-46, 1961.

CASSEL, E.J. Disease is it. Social Science and Medicine, v. 10, p.143-146, 1976.

CHAMMÉ, S.J. Poliqueixoso: metáfora ou realidade? São Paulo, 1992. [Tese de Doutorado em Saúde Pública - Faculdade de Saúde Pública da Universidade de São Paulo].

CHAMMÉ, S.J. Educação para a doença. Saúde em Debate, Brasília, n. 44, p.32-34, set., 1994.

CHAMMÉ, S.J. Modos e modas da doença e do corpo. Saúde e Sociedade, São Paulo, v. 5, n. 2, p. 61-76, 1996.

CHAMMÉ, S.J. Saúde: um processo em constante construção. Marília, 1997. [Tese de Livre-Docência em Filosofia na Faculdade de Filosofia e Ciências da Universidade Estadual de São Paulo].

CHAMMÉ, S.J. Intervenção sanitária na saúde e doença. In: CANESQUI, A.M.(org.) Ciências Sociais e saúde para o ensino médico. São Paulo: HUCITEC/FAPESP, 2000, p. 271293.

EISENBERG, I. Disease and IIIness: distinctions between professional and popular ideas of sickness. Culture, Medicine, and Psychiatry, Dordrecht, v. 1, p. 09-23, 1977.

HERZLICH, C. et PIERRET, J. De ayer a hoy: construcción social del enfermo. Cuadernos Médico-Sociales, v. 43, p. 21-30, 1988.

ILLICH, Ivan. A expropriação da saúde; Nêmesis da Medicina. Rio de Janeiro: Nova Fronteira, 1975.

LE BRETON, D. Corps et symbolique sociale. Cahiers Internationnaux de Sociologie, Paris, V. $83,1982$.

MacIVER, R.N. \& PAGE, C.H. Sociología. 2.ed. Madrid: Tecnos, 1972.

McKEOWN, T. The role of Medicine. Princeton: Princeton University Press, 1979. 
RELMAN, A.S. The power of the doctors. NYRB, 29/03/84.

RICHIR, M. Le corps: essai sur l'intériorité. Paris: HATIER, 1993.

SCLIAR, M. Do mágico ao social: a trajetória da Saúde Pública. São Paulo: L\&PM, 1987.

UNGLERT, C.V.S. Territorialização em saúde: a conquista do espaço local enquanto práticado Planejamento Ascendente. São Paulo, 1995. [Tese de Livre-Docência em Saúde Pública, da Faculdade de Saúde Pública da Universidade de São Paulo]

\title{
BODY AND HEALTH: SOCIAL INCLUSION AND EXCLUSION
}

\begin{abstract}
SUMMARY: The present article discusses the social inclusion and the exclusion concerning the body conception - here seen as a vehicle of health and disease in distinct moments of time and civilizing development levels. Thus, the $20^{\text {th }}$ century with its progresses and retreats - is potentially considered as a decisive factor in the bio-psychosocial structure and body organization, which presents itself as fragmentary, depicting the post modernity scenario. Efficiently included or not into the public policy mechanisms aiming at health promotion, such body is represented by its insertion and resonance within an unequal reality where the sick - deemed as lacking knowledge and power - is inscribed.
\end{abstract}

KEYWORDS: body; health services users; heath/disease; social inclusion; social exclusion, public policy. 